\title{
PÓS-MODERNISMO: UMA RUPTURA OU CONTINUIDADE DO MODERNISMO?
}

\author{
Reginaldo Adriano de Souza'; Mônica Oliveira Costa2; Rita de Cássia Martins de \\ Oliveira Ventura ${ }^{3}$
}

1 Formado em Administração pela Faculdade de Ciências Gerenciais de Manhuaçu. Especilaista em Docência para o Ensino Superior para a UNIP e em Administração Rural pela UFLA, mestre em Administração pela FEAD-BH. Professor e Coordenador do Curso de Marketing da Faculdade de Ciências Gerenciais de Manhuaçu.

2 Graduada em Ciências Contábeis, especialista em Controladoria e mestre em Ciências contábeis. Professora e Coordenadora do Curso de Ciências Contábeis na Faculdade de Ciências Gerenciais de Manhuaçu.

3 Bacharel em Administração pela Universidade Federal de Viçosa, mestre em Administração pela Universidade Federal de Minas Gerais, doutoranda em Ciência da Informação pela Universidade Federal de Minas Gerais. Diretora acadêmica e professora da Faculdade de Ciências Gerenciais de Manhuaçu.

\section{RESUMO}

Este artigo buscou informações sobre as teorias administrativas, bem como uma leve apresentação de suas evoluções no passar dos anos. Frente às grandes mudanças da atualidade buscou-se compreender as idéias modernistas e também entender do que se trata o modernismo. Dentro do modernismo localizou-se a Escola Clássica como sendo o principal foco do momento, onde houve uma racionalização, especialização e normatização nas formas de trabalho. Os autores pós modernos criticam essa postura exagerada de desvalorização do ser humano, que era considerado como uma continuação da máquina. No entanto, verificou-se a grande dificuldade de se entender o pós-modernismo, alguns autores consideram uma ruptura do modernismo, enquanto outros consideram uma evolução apenas. Outra dificuldade está em se projetar as características dessa nova época, uma vez que ainda se encontra em construção. Existe ainda uma fragmentação da figura humana em decorrência da diversidade, da flexibilidade e da relatividade em que se encontra o mundo atual.

PALAVRAS-CHAVES: Modernismo; pós-modernismo; mudança; organização.

\section{ABSTRACT}

This article sought information about management theories as well as a mild presentation of its evolution over the years. Despite the big changes today sought to understand modernist ideas and also understand what it is modernism. Located within modernism to Classical School as the main focus of the moment, where there was a rationalization, standardization and specialization in working arrangements. Postmodern authors criticize this exaggerated posture of devaluation of the human being, who was regarded as a continuation of the machine. However, there was great difficulty to understand postmodernism, some authors consider a break from modernism, while others consider an evolution only. Another difficulty lies in designing the features of this new era, since it is still under construction. There is also a fragmentation of the human figure because of the diversity, flexibility and relativity in which he is the current world.

KEYWORDS: modernism; postmodernism; change; organization 


\section{INTRODUÇÃO}

Competitividade, globalização, economia de escala, produção da qualidade, são alguns dos diversos assuntos levantados no meio acadêmico e administrativo das organizações neste século XXI. Nunca se falou e se questionou tanto sobre mudanças na humanidade quanto nos dias atuais, em todos os setores, nas classes sociais, nas formas de governos dos países, na postura agressiva do capitalismo, enfim o mundo tem respirado mudanças e parece ser uma das únicas certezas que temos: essa mudança terá continuidade nos anos vindouros.

Em face dessas novas perspectivas se faz válido aprofundar um pouco mais na mudança, bem como nos reflexos que trazem para o mundo administrativo. $\mathrm{Na}$ atualidade ouve-se falar em novas ferramentas de trabalho como planos de benefícios, administração participativa, empowerment, em responsabilidades ambientais e sociais, leis que regem as empresas, novas exigências do mercado consumidor, entre outras.

Novas teorias e teóricos aparecem no meio administrativo, alguns com fórmulas tidas como milagrosas no meio organizacional e acadêmico na busca das soluções dos diversos problemas surgidos nos últimos anos. Isso leva à reflexão sobre esse período conturbado de mudanças e a se questionar se realmente se vive uma ruptura do modernismo ou se ainda são seguidas as mesmas cartilhas pregadas pelos teóricos do passado. Sendo assim, o objetivo principal deste artigo é estudar essas mudanças e verificar se realmente houve uma ruptura do que era pregado na época da Revolução Industrial ou se simplesmente houve uma maquiagem das idéias do passado.

O que se pretende apresentar a seguir são as idéias defendidas pelos modernistas e pós modernista, identificando as características das épocas e alguns de seus idealizadores na tentativa de entender melhor as questões ligadas à evolução administrativa no decorrer dos anos.

\section{O MODERNISMO}

Para verificação da possível mudança advinda no novo século se faz necessário remeter ao passado não tão distante do modernismo com os seus autores e defensores. Desta forma precisa-se entender o que realmente foi 0 modernismo e quais as idéias e correntes defendidas neste contexto.

Cooper e Burrell (2007) colaboram na conceituação do termo e relatam o seguinte sobre o período moderno:

O modernismo é aquele momento em que o homem se inventou, em que ele não mais se viu como o reflexo de Deus ou da natureza. Sua origem histórica está na filosofia iluminista do século XVIII, que elegeu a Razão como o atributo humano mais elevado. A razão de acordo com Kant, significa pensar por nós mesmos e deixar de depender de alguma autoridade externa que decida por nós [...] (IBIDEM, 2007, p. 315).

Há, portanto um rompimento com tudo o que era pregado anteriormente, visto que a figura da razão entra em cena deixando o empírico e as questões religiosas em segundo plano. Motta (2007) reforça a idéia de rompimento com as tradições milenares havendo uma nova dinâmica social ditada pelos avanços tecnológicos e pela razão humana, afastando assim do mundo mítico e dando início à ciência.

Sousa (2004) corrobora com o conceito do modernismo sendo ligado à nova visão do conhecimento e da razão para a melhoria do processo produtivo para alavancar a capacidade de produção que era o grande problema da época. Segundo o autor, Weber e Taylor se apresentam como verdadeiros ícones do período moderno com a burocracia do poder e a racionalização do trabalho respectivamente. Sendo, portanto o uso de técnicas da razão e da racionalidade 
como a melhor forma de gerir as organizações e controlar o fator humano no ambiente de trabalho.

Possivelmente foi este um dos períodos em que a mudança pode ser considerada como uma das mais fortes e que trouxe reflexo em todo o mundo. Motta (2007) vincula a modernidade da administração ao período da Revolução Industrial, onde a produção artesanal deu lugar ao sistema fabril, sendo assim um marco na história da produção alterando os padrões produzidos bem como a vida social de toda a humanidade. Wood Jr. (1992) Reforça a ideia de que a vida humana sofreu grande transformação devida a nova forma de produção em massa, fortalecendo a sociedade urbana e enfraquecendo a rural e o humanismo cedendo espaço ao racionalismo.

Sacomano Neto e Truzzi (2002) citam que Hatch ${ }^{1}$ apresentou um momento de impulso no mundo administrativo e produtivo, que é justamente a industrialização norte-americana e inglesa, onde os estudos organizacionais ganharam peso e as abordagens de gestão passaram a ser analisadas cientificamente. Apontam ainda os trabalhos de Taylor, Fayol e Barnard como precursores de análises e práticas operacionais, propondo soluções para os problemas enfrentados na época.

\section{a. Os três pilares do modernismo administrativo}

Como ressaltado anteriormente alguns teóricos se destacaram como ícones do modernismo e cabe então um breve acompanhamento das idéias defendidas por Taylor, Fayol e Max Weber.

Taylor (2011), considerados por muitos como o pai da administração, pregava a divisão das tarefas como forma de tornar o empregado mais especialista aumentando assim seu aspecto produtivo. Era, portanto, a substituição do empirismo por métodos científicos onde através dos

\footnotetext{
${ }^{1}$ HATCH, M.J. Organization theory. Oxford University Press, 1997.
}

estudos do tempo e dos movimentos aliados à divisão das tarefas levaria o homem à maior produtividade.

O autor afirma ainda que os interesses de empregadores e empregados não são antagônicos, uma vez que os mesmo precisam prosperar conjuntamente. A forma de alcançar os objetivos era, de um lado, o empregado receber altos salários de por outro lado o empregador atingir baixos custos produtivos pela alta produtividade. Taylor (2011) apresentava uma visão pessimista do ser humano, considerando-o vadio, por não se esforçar tanto no trabalho como em outras áreas de sua vida como o esporte, por exemplo. Surge então a figura do homem econômico que trabalha por medo de passar fome e que a fonte de satisfação do empregado é o dinheiro.

Wood Jr (1992, p.3) faz algumas considerações a cerca do taylorismo que podem sintetizar parte das idéias de Frederick:

Taylor desenvolveu uma série de princípios práticos baseados na separação entre trabalho mental e físico e na fragmentação das tarefas. Estes princípios são aplicados até hoje tanto nas fábricas como nos escritórios. O efeito direto da aplicação desses princípios foi a configuração de urna nova força de trabalho marcada pela perda das habilidades genéricas manuais $e$ um aumento brutal da produtividade. Por outro lado, passaram a surgir problemas crônicos como absenteísmo e elevado turnover.

Outro colaborador de significativa importância do modernismo foi Henry Fayol. A Teoria Clássica de Fayol complementa 0 trabalho de Taylor, propondo a racionalidade da estrutura administrativa com a departamentalização dos setores. O teórico criou os princípios da boa administração, apresentando as funções clássicas do administrador que segundo ele era: planejar, organizar, coordenar, comandar e controlar. 
Princípios como a unidade de comando e definição clara de responsabilidade e autoridades torna-se fatores chaves para o êxito organizacional. (WOOD JR, 1992).

Desta forma percebe-se que os estudos de Taylor são complementares ao de Fayol, enquanto um foca a divisão e padronização das tarefas no sistema produtivo o outro contempla a mesma divisão e padronização no setor estrutural da empresa.

Max Weber é outra imagem forte do modernismo ele observou a mecanização da indústria e pregou a proliferação das normas burocráticas de organização. "Segundo ele, a burocracia rotiniza a administração como as máquinas rotinizam a produção." (WOOD $J R$, 1992). As normas e regras passaram a ser utilizadas de forma mais intensa na busca de uma maior organização nas empresas, profissionalismo era outra idéia forte defendida por Weber. Essas concepções de Weber contribuem ainda mais para a especialização e para criação de uma rotina a ser seguida pelos operários da época.

Segundo DiMaggio e Powel (1983) a burocracia é um meio poderoso e eficiente para controlar homens e mulheres, tanto que ficou conhecida como jaula de ferro, ainda segundo os autores, Weber afirma que os controles organizacionais, através das normas e regras, são exigidos para que as organizações honrassem seus compromissos legais.

\section{b. O enfraquecimento do modernismo}

As organizações passam por mudanças no decorrer dos tempos devido a diversos fatores como: concorrência, economia, globalização, maior poder dos consumidores, exigências sociais e ambientais. Carnall ${ }^{2}$ apud Grey (2004, p.3) assevera que:

\footnotetext{
${ }^{2}$ CARNALL, C. Managing change in organizations. London: Prentice-Hall, 1995.
}

Em um mundo de mudanças, a única constante é a mudança... a realidade é que a estabilidade que parecia caracterizar 0 mundo organizacional nos anos 1950 e 1960 deu espaço para uma crescente e global competição, para as inovações e mudanças tecnológicas, para a limitação de recursos, a desregulamentação, a privatização das organizações públicas, e mudanças em muitas outras áreas.

Conforme verificado acima as mudanças são inevitáveis e se tornaram uma constante no dia a dia das organizações. Com essas mudanças há sempre uma possibilidade de quebra de paradigmas, podendo, portanto trazer tanto rupturas quanto evoluções nos processos anteriores. Souza (2004, p.2) afirma que várias mudanças contribuíram para a queda do modernismo, entre elas: "a globalização dos mercados; o crescimento das organizações; a rápida implementação e aplicação das tecnologias de comunicação e informação; mudança com relação à natureza do trabalho; a profissionalização da força produtiva; economias estagnadas; movimentos ecológicos; a fácil movimentação do capital; [...]".

Uma crítica forte ao modernismo é aferida por Motta (2007) dizendo que a modernidade apresentou um resultado incompleto por ter servido a apenas uma parcela da humanidade, o que aumentou as desigualdades. De forma clara a parcela mais prejudicada na época foi a dos trabalhadores que eram controlados excessivamente, sendo considerados como uma parte das máquinas.

Wood Jr. (1992) apresenta a mudança advinda da nova concepção do ser humano, neste contexto começou-se a verificar as necessidades humanas. Como não poderia deixar de ser cita Elton Mayo como um dos primeiros a identificar as necessidades dos trabalhadores e a importância dos grupos informais. Elucida ainda a figura de Maslow dispondo as necessidades humanas em uma pirâmide 
hierárquica, Herzberg e Mcgregor abordando a integração dos indivíduos nas organizações, indivíduos esses como fontes de criatividade e inovação. Em face deste novo contexto surgem os conceitos de Gerenciamento dos Recursos Humanos e a valorização das pessoas nas empresas.

Tureta et al (2005) contribuem com a visão sistêmica das organizações atuais, nos tempos passados na Escola Clássica (Taylor, Fayol e Weber) e até mesmo na Escola das Relações Humanas (Mayo) as organizações eram consideradas como sendo sistema fechado. Eles asseveram que na realidade as organizações atuais apresentam intercâmbio com o ambiente onde estão inseridas, influenciando e sendo influenciadas por essa estrutura ambiental externa. Esses fatores (estratégia, tamanho, tecnologia, concorrência, entre outros) trazem incertezas para a organização, pois nada é tão previsível como era pregado na modernidade.

\section{c. Posmodernismo ou pós- modernismo:}

Todas essas mudanças a cerca da concepção humana e das estruturas do mercado competitivo trouxeram consigo uma nova visão no mundo administrativo, gerando novos conceitos como modernismo e pós-modernismo. Estes conceitos são de difícil conceituação por representarem possivelmente uma atualidade ainda em construção.

Segundo Sousa (2004, p.4) "o pósmodernismo surgiu como uma forma de rebeldia contra os "abusos" cometidos em nome da cientificidade da racionalidade instrumental do modernismo, que de uma forma ou de outra, serve como ferramenta de dominação de um grupo de "privilegiados" perante os demais mortais, postergando aquilo que a princípio este combatia: que era o mito, a tradição." É portanto uma quebra da continuidade da dominação pregada pelo modernismo, é a desconstrução da desvalorização humana e da falsa idéia de que todos ganhavam no processo produtivo da época.
Essa idéia de ruptura é questionada por alguns nomes como Giddens que aceita mudanças fundamentais na época, mas não uma ruptura total, assim sendo ele acredita que "o pós-moderno é a continuidade das mesmas práticas sociais apenas em contextos históricos diversos." (MOTTA, 2007 , p. 11). O autor assevera ainda que há uma extrema dificuldade com esses termos, além do mais não se tem um parâmetro de quando se tem início as questões que sucedem o modernismo. Não somente há complicações quanto à raiz do termo pós-moderno, mas também uma dificuldade de entendimento das características que envolvem 0 mundo atual, fato é que muitas características modernistas também são pertinentes às definições de pós modernismo.

Sousa (2004) afirma ser uma característica das organizações pós modernas o grande fluxo de informações e a presença de uma cultura mais forte nas empresas, onde começa a existir uma maior presença do trabalho flexível, da informalidade, da descentralização e consequentemente uma gestão mais participativa. $\mathrm{O}$ autor critica ainda a forma como a Burocracia prende a figura humana e afirma que tanto as pessoas quanto a gestão das organizações não estão mais interessados na racionalidade burocrata.

No entanto, separar onde termina o modernismo e inicia o pós modernismo é algo extremamente complexo, não havendo um grande marco. Power ${ }^{3}$ apud Sousa $(2004$, p.3) relata que "não há uma linha absoluta que demarca a diferença entre o que é moderno e o que é pós moderno. Para alguns autores, pós moderno pode significar tanto o término como uma continuação diferente da modernidade". Existe ainda uma grande dificuldade e até mesmo um impasse no que diz respeito a corrente pós moderna, alguns autores consideram a continuidade

\footnotetext{
${ }^{3}$ POWER, M. Modernism, Postmodernism and Organization. in HASSARD, J. PYM,D. The theory and philosophy of organizations. London: Routledge, 1990.
} 
do modernismo enquanto outros consideram uma ruptura.

Vieira e Caldas (2006) apresentam algumas características tidas como pósmodernas baseados nos estudos de Harvey e Derrida: globalização; o relativismo e 0 pluralismo; espetacularização da sociedade; a cultura de massa; a normalização da mudança onde tudo é volátil e transitório; o consumidor ganhando papel de destaque na sociedade; e a comoditização do conhecimento. Vieira e Caldas (2006) elucidam ainda a divisão das duas correntes de pós-modernismo, onde autores como Giddens ou Habermas consideram a atualidade como um estágio tardio da modernidade, não se pode negar a razão (se negaria o valor do indivíduo) nem o projeto iluminista (que ainda não está completo, portanto a modernidade perdura até os dias atuais).

Sousa (2004) reforça a idéia de que as teorias pós-modernistas são extremamente novas e difíceis de serem entendidas, no entanto trata 0 pos modernismo como algo real e não apenas como modismo. Reafirma ainda influências epistemológicas são de diversas áreas o que dificulta prever sua identidade e espera ainda não ser mais uma forma disfarçada de dominação. $\mathrm{O}$ autor divide então os termos, sendo caracterizado pos modernismo a corrente que prega a continuidade do moderno, havendo, portanto uma dependência do modernismo e caracteriza ainda o pósmodernismo como uma forma rebelde contrária aos abusos do modernismo quebrando essa continuidade e, portanto pregando uma desconstrução. Sousa (2004) afirma ainda que o pósmodernismo receba duras críticas devido a sua desorganização que o leva a beira do caos, até mesmo por ainda estar em construção. E também pela dificuldade de delimitar esse pós-modernismo.

Bauman ${ }^{4}$ apud Chevitarese (2001, p.12) reforça a idéia de que não existe

\footnotetext{
${ }^{4}$ BAUMAN, Zygmunt: Modernidade e Ambivalência. RJ. Jorge Zahar Editor. 1999.
}

uma ruptura entre modernismo e posmodernismo:

a pós-modernidade é a
modernidade que atinge a
maioridade, a modernidade
olhando-se a distância e não de
dentro, fazendo um inventário
completo de ganhos e perdas,
psicanalizando-se, descobrindo as
intenções que jamais explicitara,
descobrindo que elas são
mutuamente incongruentes e se
cancelam. A pós-modernidade é a
modernidade chegando a um
acordo com a sua própria
impossibilidade, uma modernidade
que se automonitora, que
conscientemente descarta o que
outrora fazia inconscientemente.

Desta forma Chevitarese (2001, p.12) acredita que "o "pós" de "pósmodernidade" não pode denotar, de fato, ruptura ou esgotamento da modernidade, não pode significar seu obituário". Desta forma acredita ter uma ligação com as práticas modernistas do passado e não uma negação total.

Com relação à gestão das empresas nos dias atuais ainda pode-se perceber a forte influencia do modernismo em algumas organizações. A administração científica e a burocracia, bem como suas idéias de controle do ser humano, ainda se fazem presentes no nosso dia-a-dia. Guimarães (2006) afirma que na atualidade existem outros tipos de controle que tem ultrapassado as questões do corpo chegando a controlar a mente do trabalhador. "A organização e seus gestores passaram a se utilizar de técnicas, políticas e práticas organizacionais que visam o controle do trabalhador sem, contudo, parecer que estão controlando." (IBDEM, 2006, p.4).

\section{CONSIDERAÇÕES FINAIS:}

De acordo com o apresentado ainda existem diferentes formas de entender o momento administrativo que se apresenta depois do modernismo. Como exposto alguns autores afirmam haver 
uma ruptura do modernismo com os dias contemporâneos, no entanto outros acreditam apenas em uma evolução e que as práticas gerenciais foram apenas maquiadas. Apresentou ainda que algumas formas de gerir apenas passaram por mudanças terminológicas, mas que ainda controlam o colaborador da mesma forma, ou até mais forte, do que no passado.

Pode-se perceber que ainda é uma grande novidade o temo pós modernidade e suas características, mesmo que se pregue uma ruptura do modernismo ainda há uma necessidade de conceitos e até mesmo atitudes modernistas dentro deste novo contexto. Neste mundo pluralista onde nada mais é uma totalidade, onde existe uma relatividade nas ações e formas de pensar humanas torna-se ainda mais complexo entender o momento que vivemos, bem como conceituá-lo e apontar suas principais características.

Deve-se ressaltar ainda que nem todos os tipos de organização se enquadram totalmente neste contexto de pós moderno. As empresas mecanicistas que produzem em massa, mesmo na era pós moderna seguem muitos padrões do modernismo. Percebe-se, portanto, que não existe uma verdade absoluta que permeia 0 meio administrativo e que realmente ainda vivemos em um meio contingencial onde as atitudes administrativas dependem de situações em que se encontra em determinado momento.

Desta forma considera-se aqui que vivenciamos uma evolução no tempo e na forma de gerir as organizações, sem, no entanto poder afirmar que existe uma ruptura total. Entende-se que traços modernistas são presentes no cotidiano das organizações atuais e que colaboram para a perenização das mesmas em um meio tão competitivo e globalizado.

\section{REFERÊNCIAS BIBLIOGRÁFICAS:}

CHEVITARESE, L. (2001): “As 'Razões' da Pós-modernidade". In: Analógos.
Anais da I SAF-PUC. RJ: Disponível em http://www.saude.inf.br/artigos/posmoderni dade.pdf. Acesso: 20/08/2011.

COOPER, Robert; BURRELL, Gibson. Modernismo, pós-modernismo e análise organizacional: uma introdução. RAE, Rio de Janeiro: FGV, v. 46, n. 1, p. 87-101, jan./mar. 2006.

DiMAGGIO, P. J.; POWELL, W. W. A gaiola de ferro revisitada: isomorfismo institucional e racionalidade coletiva nos campos organizacionais. Revista de Administração de Empresas, v. 45, n. 2, p. 72-89, 2005.

FREITAS, M. E. Cultura Organizacional: Evolução e Crítica. São Paulo: Thomson, 2007.

GREY, C. O fetiche da mudança. RAE, Rio de Janeiro: FGV, v. 44, n. 1, jan./mar. $2004 . \quad$ Disponível em: http://rae.fgv.br/sites/rae.fgv.br/files/artigos /10.1590_S003475902004000100002.pdf.

Acesso: 19/08/2011.

GUIMARAES, Magali Costa. Controle no trabalho: uma reflexão sobre antigas e novas formas de controle e suas conseqüências sobre os trabalhadores. REGE-USP [online]. 2006, vol.13, n.1, pp. 1-10. Disponível em http://www.revistasusp.sibi.usp.br/pdf/rege /v13n1/v13n1a1.pdf. Acesso 15/08/2011.

MOTTA, P. R. Transformação organizacional: a teoria e a prática de inovar - Rio de Janeiro: Qualitymark Ed., 6⿳亠丷厂 reimpressão, 2007.

SACOMANO NETO, M. e TRUZZI, O.M.S. Perspectivas Contemporâneas em análise organizacional. São Paulo, UFSCAR: Gestão \& Produção v.9, n.1, p.32-44, abr. 2002.

SOUSA, Paulo Daniel Batista de. Posmodernismo e a Teoria Organizacional Contemporânea in III Seminário do Centro de Ciências Sociais Aplicadas. 
UFPR: Cascavel - 18 a 22 de Outubro de 2004.

TAYLOR, W. T. Princípios de administração científica. Tradução Arlindo Vieira Ramos. 8. ed. São Paulo: Atlas, 2011

TURETA, Cesar at al. Da teoria sistêmica ao conceito de redes interorganizacionais: um estudo exploratório da teoria das organizações. II Seminário de gestão de negócios, FAE: Curitiba, 2005.

VIEIRA, M. M. F.; CALDAS. M. P. Teoria crítica e pós-modernismo: principais alternativas à hegemonia funcionalista. RAE, Rio de Janeiro: FGV, v. 46, n. 1, p. 59-70, jan./mar. 2006

WOOD JR, Thomaz. Fordismo, Toyotismo e Volvismo. Os caminhos da indústria em busca do tempo perdido. Revista de Administração de Empresas, São Paulo, v. 32, n.4, set./out. 1992, p.6-18. 